\title{
Antioxidant or Apoptosis Inhibitor Supplementation in Culture Media Improves Post-Thaw Recovery of Murine Spermatogonial Stem Cells
}

\author{
Sang-Eun Jung ${ }^{1,+}$, Hui-Jo Oh ${ }^{1,+}$, Jin-Seop Ahn ${ }^{1}\left(\mathbb{D}\right.$, Yong-Hee Kim ${ }^{1}$, Bang-Jin Kim ${ }^{2}$ and Buom-Yong Ryu ${ }^{1, *(1)}$ \\ 1 Department of Animal Science and Technology, Chung-Ang University, \\ Anseong-si 17546, Gyeonggi-do, Korea; tkddms2428@naver.com (S.-E.J.); gmlwh780128@naver.com (H.-J.O.); \\ ahnjs@cau.ac.kr (J.-S.A.); yhkcau@naver.com (Y.-H.K.) \\ 2 Department of Cancer Biology, Perelman School of Medicine, University of Pennsylvania, \\ Philadelphia, PA 19104, USA; bakim@mail.med.upenn.edu \\ * Correspondence: byryu@cau.ac.kr; Tel.: +82-31-670-4687 \\ + These authors contributed equally to this work.
}

Citation: Jung, S.-E.; Oh, H.-J.; Ahn, J.S.; Kim, Y.-H.; Kim, B.-J.; Ryu, B.-Y Antioxidant or Apoptosis Inhibitor Supplementation in Culture Media Improves Post-Thaw Recovery of Murine Spermatogonial Stem Cells. Antioxidants 2021, 10, 754. https:// doi.org/10.3390/antiox10050754

Academic Editor: Consuelo Borras

Received: 9 March 2021

Accepted: 6 May 2021

Published: 10 May 2021

Publisher's Note: MDPI stays neutral with regard to jurisdictional claims in published maps and institutional affiliations.

Copyright: (c) 2021 by the authors. Licensee MDPI, Basel, Switzerland. This article is an open access article distributed under the terms and conditions of the Creative Commons Attribution (CC BY) license (https:// creativecommons.org/licenses/by/ $4.0 /)$.

\begin{abstract}
We postulated that supplementation of antioxidant or apoptosis inhibitor in post-thaw culture media of spermatogonial stem cells (SSCs) alleviates reactive oxygen species (ROS) generation and apoptosis. Our aim was to develop an effective culture media for improving post-thaw recovery of SSCs. To determine the efficacy of supplementation with hypotaurine (HTU), $\alpha$-tocopherol $(\alpha$ TCP), and Z-DEVD-FMK (ZDF), we assessed the relative proliferation rate and SSC functional activity and performed a ROS generation assay, apoptosis assay, and western blotting for determination of the Bax/Bcl-xL ratio, as well as immunocytochemistry and real-time quantitative polymerase chain reaction (RT-qPCR) for SSC characterization. The relative proliferation rates with HTU $400 \mu \mathrm{M}$ $(133.7 \pm 3.2 \%), \alpha$-TCP $400 \mu \mathrm{M}(158.9 \pm 3.6 \%)$, and ZDF $200 \mu \mathrm{M}(133.1 \pm 7.6 \%)$ supplementation were higher than that in the DMSO control $(100 \pm 3.6 \%)$. ROS generation was reduced with $\alpha$-TCP $400 \mu \mathrm{M}$ (0.8-fold) supplementation in comparison with the control (1.0-fold). Early apoptosis and Bax/Bcl-xL were lower with $\alpha$-TCP $400 \mu \mathrm{M}(2.4 \pm 0.4 \%$ and 0.5 -fold $)$ and ZDF $200 \mu \mathrm{M}(1.8 \pm 0.4 \%$ and 0.3 -fold) supplementation in comparison with the control (5.3 $\pm 1.4 \%$ and 1.0-fold) with normal characterization and functional activity. Supplementation of post-thaw culture media with $\alpha$-TCP $400 \mu \mathrm{M}$ and ZDF $200 \mu \mathrm{M}$ improved post-thaw recovery of frozen SSCs via protection from ROS generation and apoptosis after cryo-thawing.
\end{abstract}

Keywords: permatogonial stem cells; post-thaw recovery; reactive oxygen species; antioxidant; apoptosis

\section{Introduction}

Spermatogonial stem cells (SSCs) are the basis for spermatogenesis through selfrenewal and differentiation in the outer wall of the seminiferous tubules of testes. Even if the proportion of SSC is only $\sim 0.01 \%$ in mice testes, one SSC can theoretically produce 4096 sperm cells that eventually produce progeny for the next generation via fertilization [1]. Therefore, SSCs are a pivotal resource for continuity of the male germline. SSC cryopreservation can facilitate the application of these cells in various fields (e.g., restoration of male fertility in the clinic, preservation of valuable animal breeding stocks, and stem cell research) [2-4]. However, cryopreservation is associated with problems such as apoptotic cell death followed by reactive oxygen species (ROS) attack after cryo-thawing, which reduces the efficiency of post-thaw recovery $[5,6]$.

To overcome these ROS attacks in frozen cells, attempts have been made to develop freezing media containing antioxidants and/or apoptosis inhibitors [7-9]. In particular, hypotaurine (HTU), a sulfur-containing amino acid with antioxidant capacity, has shown 
beneficial effects as a cryoprotectant in freezing media for germ cell cryopreservation [9-11]. Moreover, $\alpha$-tocopherol ( $\alpha$-TCP), a non-enzymatic antioxidant, has also shown protective effects against ROS-induced protein damage, lipid peroxidation, and inhibition of cellular mechanisms in germ cell cryopreservation [12-14]. Additionally, supplementation of ZDEVD-FMK (ZDF), a caspase-3 inhibitor, in freezing media has been shown to attenuate cryoinjury-induced apoptosis in mesenchymal stem cell cryopreservation [15].

Despite these efforts, however, these freezing media still have limited ability to reduce cryoinjury of cultured cells after thawing. Furthermore, because major cryoinjury happens in the early stages after cryo-thawing [16], new approaches are required to suppress post-thaw cryoinjury. Accordingly, many reports have demonstrated that pre- or postcryopreservation care using a culture media with antioxidants or apoptosis inhibitors would allow improved post-thaw recovery in sperm, oocytes, embryos, human embryonic stem cells, and human mesenchymal stem cells [7,17-22]. They also demonstrated that supplementation in post-thaw culture media is more effective than that in freezing media. Nevertheless, no previous studies have assessed the efficiency of culture media with antioxidants and apoptosis inhibitors in post-thaw recovery in SSC cryopreservation.

In this regard, we postulated that supplementation of antioxidants or apoptosis inhibitors in post-thaw culture media would alleviate ROS generation and the apoptosis of cryo-thawed SSCs. We aimed to develop an effective culture media for improving postthaw recovery of SSCs. This study provides a promising approach to improve post-thaw recovery of SSC, which can facilitate widespread SSC utilization in male infertility clinics and/or animal industries.

\section{Materials and Methods}

\subsection{Experimental Animals}

The animal experiments were approved by the Animal Care and Use Committee of Chung-Ang University (Permit Number: 201900048) and were conducted according to the Guide for the Care and Use of Laboratory Animals published by the National Institutes of Health. The animal room was maintained at a constant temperature of $23 \pm 1{ }^{\circ} \mathrm{C}$ and humidity of $55 \pm 10 \%$ under a 12-h light/dark cycle. The C57BL/ 6 (designated C57; DooYeol Biotech, Seoul, Korea) and C57BL/6-TG-EGFP (designated C57-GFP; Jackson Laboratory, Bar Harbor, ME, USA) strains were used as recipient and donor mice, respectively. The donor cells derived from C57-GFP mice could be easily distinguished from those of the C57 recipient mice in in vivo transplantation since the donor cells expressed the enhanced green fluorescent protein (EGFP).

\subsection{Isolation and Culture of Germ Cells Enriched for SSCs}

Unless otherwise noted, all reagents were purchased from Sigma-Aldrich (St. Louis, $\mathrm{MO}, \mathrm{USA}$ ). A total of five cell lines isolated from each litter were used in this study. Germ cells enriched for SSCs were obtained as previously described [23]. Briefly, testes of 6-8-dayold C57-GFP mice were isolated to obtain germ cells enriched for SSCs. After decapsulation of the tunica albuginea, the seminiferous tubules were washed in Dulbecco's phosphatebuffered saline (DBPS; Life Technologies, Grand Island, NY, USA) and treated in a 2:1 mixture of $0.25 \%$ trypsin-EDTA (Invitrogen, Carlsbad, CA, USA) and $7 \mathrm{mg} / \mathrm{mL}$ DNase I (Roche, Basel, Switzerland) in DBPS at $37^{\circ} \mathrm{C}$ for $5 \mathrm{~min}$ to obtain testicular single cells. The digested testicular cells were filtered through a $40-\mu \mathrm{m}$ cell strainer (BD Biosciences, San Jose, CA, USA), and the filtered testicular cells were then centrifuged at $600 \times g$ for $7 \mathrm{~min}$ at $4{ }^{\circ} \mathrm{C}$. After removing the supernatant, the pallet was resuspended in Dulbecco's Modified Eagle Medium (DMEM; Life Technologies) containing 10\% fetal bovine serum (FBS), $0.1 \mathrm{mM}$ $\beta$-mercaptoethanol, $2 \mathrm{mM}$ L-glutamine, $100 \mu \mathrm{g} / \mathrm{mL}$ streptomycin, and $100 \mathrm{U} / \mathrm{mL}$ penicillin to $5 \times 10^{6}$ cells $/ \mathrm{mL}$. Erythrocytes and cellular debris were removed using a $30 \%$ Percoll gradient. Single cells were incubated with anti-Thy- 1 antibody microbeads (Miltenyi Biotech, Auburn, CA, USA) in FBS $1 \%$ in DPBS for 15 min at $4{ }^{\circ} \mathrm{C}$ and enriched via magneticactivated cell sorting [24]. Thy- $1^{+}$germ cells enriched for SSCs (designated germ cells 
enriched for SSCs) were cultured on mitotically inactivated SIM mouse embryo-derived thioguanine- and ouabain-resistant (STO) feeder cells in a defined mouse serum-free medium (mSFM, Table 1) consisting of $10 \mathrm{ng} / \mathrm{mL}$ glial cell line-derived neurotrophic factor (GDNF; R\&D Systems, Minneapolis, MN, USA), $75 \mathrm{ng} / \mathrm{mL}$ GDNF family receptor alpha 1 (GFR $\alpha 1$; R\&D Systems), and $1 \mathrm{ng} / \mathrm{mL}$ basic fibroblast growth factor (bFGF; Corning, Midland, MI, USA) [25]. These germ cells enriched for SSCs were passaged once weekly.

Table 1. Composition of mouse serum-free media (mSFM).

\begin{tabular}{|c|c|}
\hline Ingredients $^{a}$ & Final Concentration \\
\hline Penicillin & 50 unit $/ \mathrm{mL}$ \\
\hline Streptomycin & $50 \mu \mathrm{g} / \mathrm{mL}$ \\
\hline Bovine serum albumin & $0.2 \%$ \\
\hline Iron-saturated transferrin & $10 \mu \mathrm{g} / \mathrm{mL}$ \\
\hline Free fatty acids & $7.8 \mu \mathrm{Eq} / \mathrm{L}$ \\
\hline $\mathrm{Na} 2 \mathrm{SeO} 3$ & $3 \times 10^{-8} \mathrm{M}$ \\
\hline L-Glutamine & $2 \mathrm{mM}$ \\
\hline 2-Mercaptoethanol & $50 \mu g$ \\
\hline Insulin & $5 \mu \mathrm{g} / \mathrm{mL}$ \\
\hline N-2-hydroxyethylpiperazine- $N^{\prime}$-2-ethanesulfonic acid (HEPES) & $10 \mathrm{mM}$ \\
\hline Putrescine & $60 \mu \mathrm{M}$ \\
\hline
\end{tabular}

a All ingredients were diluted in Eagle's minimum essential medium-alpha (MEM- $\alpha$, Invitrogen).

\subsection{Cryopreservation}

In our previous study, we developed an effective cryoprotectant for SSC freezing, consisting of DMSO 10\%, FBS 10\%, and trehalose $200 \mathrm{mM}$ in DPBS [26], which was used as the control in the present study. Trehalose was dissolved in DPBS to prepare solution-1 (trehalose $400 \mathrm{mM}$ in DPBS), and, for freezing, cultured germ cells $\left(2 \times 10^{6}\right.$ cells/vial, 8-18 passages) were first suspended in $500 \mu \mathrm{L}$ of this solution- 1 and immediately diluted with the same volume of solution-2 (DMSO 20\% and FBS 20\% in DPBS) in a dropwise manner. The cell suspensions were transferred to 1.8-mL cryovials (Corning), placed into a Nalgene ${ }^{\circledR}$ freezing container (Nalgene, Rochester, NY, USA) containing isopropyl alcohol, and stored at $-80{ }^{\circ} \mathrm{C}$ overnight in a deep freezer. The vials were then transferred and stored in liquid nitrogen for at least one month.

\subsection{Evaluation of the Relative Proliferation Rate after Antioxidant or Apoptosis Inhibitor Treatment}

All reagents were prepared before use. To prepare stock solutions, hypotaurine (HTU; Sigma, H1384, powder), $\alpha$-tocopherol ( $\alpha$-TCP; Sigma, T3251, liquid), and Z-DEVEFMK (ZDF; TOCRIS, 2166, lyophilized solid) were dissolved in distilled water, ethanol, and DMSO, respectively, and these were diluted 1:1000 with mSFM before use. The concentration of antioxidant/apoptosis inhibitor was defined as 50-400 $\mu \mathrm{M}$, including the effective concentrations of each reagent (i.e., $200 \mu \mathrm{M} \alpha$-TCP, $100 \mu \mathrm{M}$ HTU, and $100 \mu \mathrm{M}$ ZDF) $[12,27,28]$. After thawing at $37^{\circ} \mathrm{C}$ for $2.5 \mathrm{~min}$, the germ cell suspension was diluted with $10 \mathrm{~mL}$ of a thawing medium (FBS 10\% in Minimum Essential Medium- $\alpha$; Gibco, Grand Island, NY, USA). After washing in $\mathrm{mSFM}$, the same number of thawed germ cells was plated onto a 24 -well plate $\left(2 \times 10^{5}\right.$ cells/well $)$. Immediately after thawing, the germ cells were cultured in media (mSFM with $10 \mathrm{ng} / \mathrm{mL}$ GDNF, $75 \mathrm{ng} / \mathrm{mL}$ GFR $\alpha 1$, and $1 \mathrm{ng} / \mathrm{mL}$ bFGF2) containing different concentrations of each antioxidant or apoptosis inhibitor (Table 2) for $12 \mathrm{~h}$ in a $5 \% \mathrm{CO}_{2}$ incubator at $37^{\circ} \mathrm{C}$, based on the findings suggesting that major cryoinjury occurs within the first 12-24 h after cryo-thawing [16]; the cells were then cultured under normal culture conditions without the antioxidant or apoptosis inhibitor for 6.5 days. Subsequently, the germ cells were dissociated with $0.25 \%$ trypsin and manually pipetted. After centrifugation at $600 \times g$ for $7 \mathrm{~min}$ at $4{ }^{\circ} \mathrm{C}$, the pellet was resuspended in $\mathrm{mSFM}$, and the relative proliferation rate (\%) was calculated as follows: 
Proliferation rate $(\%)=$ number of cells recovered after cryo-thawing and culture $\times 100 /$ number of initial cells plated after cryo-thawing $\left(2 \times 10^{5}\right)$

Relative proliferation rate $(\%)=$ proliferation rate of treatment groups $\times 100 /$ proliferation rate of control groups

Table 2. Antioxidants and apoptosis inhibitor used for post-thaw recovery.

\begin{tabular}{cccccc}
\hline Reagent & Property & \multicolumn{3}{c}{ Final Concentration $(\mu \mathbf{M})$} \\
\hline Hypotaurine $(\mathrm{HTU})$ & Antioxidant & 50 & 100 & 200 & 400 \\
$\alpha$-Tocopherol $(\alpha-\mathrm{TCP})$ & Antioxidant & 50 & 100 & 200 & 400 \\
Z-DEVD-FMK $($ ZDF) & Apoptosis inhibitor & 50 & 100 & 200 & 400 \\
\hline
\end{tabular}

The control group included frozen germ cells with no treatment.

\subsection{ROS Generation Assay}

After cryo-thawing, the resuspended germ cells $\left(5 \times 10^{4}\right.$ cells/well $)$ were seeded on wells of a 96-well plate. At $12 \mathrm{~h}$ after incubation without or with antioxidants or the apoptosis inhibitor, a DCFDA cellular ROS detection assay (Abcam, Cambridge, UK) was used according to the manufacturer's instructions to analyze the ROS level within the germ cells enriched for SSCs. Briefly, the germ cells enriched for SSCs were washed by DPBS to eliminate antioxidants and incubated with $25 \mu \mathrm{M}$ DCFDA solution in a $5 \% \mathrm{CO}_{2}$ incubator at $37^{\circ} \mathrm{C}$ for $30 \mathrm{~min}$. Fluorescence intensity was measured by a fluorescence microplate reader (Gemini XS, Molecular Devices, Sunnyvale, CA, USA) for excitation and emission spectra at 485 and $535 \mathrm{~nm}$, respectively.

\subsection{Apoptosis Assay}

Germ cells were harvested $12 \mathrm{~h}$ after thawing and culturing without or with each reagent in a $5 \% \mathrm{CO}_{2}$ incubator at $37^{\circ} \mathrm{C}$. After washing in cold DPBS, the pellet was resuspended in $1 \times$ binding buffer (BD Biosciences), and the cell suspension $\left(1 \times 10^{5}\right.$ cells) was then transferred to a new tube. The cell suspension was incubated in annexin VAPC (BD Biosciences) and propidium iodide (PI) for $15 \mathrm{~min}$ at RT $\left(20-25^{\circ} \mathrm{C}\right)$ in the dark. Apoptotic cells were assessed using flow cytometry with a FACSAria II cell sorter (BD Biosciences) equipped with BD CellQuest ${ }^{\mathrm{TM}}$ Pro software (Becton Dickinson, Oxford, UK).

\subsection{Western Blot}

Germ cells were collected after $12 \mathrm{~h}$ of incubation without or with each antioxidant or apoptosis inhibitor in a $5 \% \mathrm{CO}_{2}$ incubator at $37^{\circ} \mathrm{C}$. Proteins were extracted using an RIPA buffer (Thermo Fisher Scientific, Rockford, IL, USA) consisting of protease inhibitor and phosphatase inhibitor cocktails (Thermo Fisher Scientific). The lysate was centrifugated at 13,000 rpm for $20 \mathrm{~min}$ at $4{ }^{\circ} \mathrm{C}$, after which supernatants were collected. Protein quantification was conducted using a BCA protein assay (Thermo Fisher Scientific), and $5 \mu \mathrm{g}$ of each protein was loaded onto a $15 \%$ SDS-polyacrylamide gel. The separated protein was blotted onto a polyvinylidene difluoride (PVDF) membrane (Millipore, Billerica, MA, USA), which was blocked with $5 \%$ skim milk in DPBS containing $0.2 \%$ Tween 20 (PBS-T) at RT $\left(20-25^{\circ} \mathrm{C}\right)$ for $2 \mathrm{~h}$. After washing in PBS-T, the membrane was incubated with primary antibodies diluted 1:1000 at $4{ }^{\circ} \mathrm{C}$ overnight: rabbit anti-Bcl-xL (2764S, Cell Signaling Technology (CST), Danvers, MA, USA) and rabbit anti-Bax (14792, CST). Mouse anti- $\alpha$-tubulin (ab7291, Abcam) at a 1:5000 dilution was used as a loading control. After washing in PBS-T, HRP-conjugated secondary antibody diluted 1:2000 was treated at RT $\left(20-25^{\circ} \mathrm{C}\right)$ for $2 \mathrm{~h}$; anti-rabbit IgG $(7074 \mathrm{~S}, \mathrm{CST})$ and anti-mouse IgG (7076S, CST) were used as secondary antibodies. Protein expression was detected using the electrochemiluminescence (ECL) method, and the band intensity was evaluated using ImageJ software (version 1.8.0, National Institutes of Health, Bethesda, MD, USA). 


\subsection{Immunofluorescence}

After a week of in vitro culture following cryo-thawing and treatment with the reagents, the germ cells were collected and fixed with $4 \%$ paraformaldehyde (Biosesang, Seongnam, Korea) at RT $\left(20-25{ }^{\circ} \mathrm{C}\right)$ for $30 \mathrm{~min}$. The cells were then permeabilized with $0.1 \%$ Triton X-100 $(v / v)$ in DPBS at RT $\left(20-25^{\circ} \mathrm{C}\right)$ for $10 \mathrm{~min}$. After blocking with $5 \%$ bovine serum albumin for $1 \mathrm{~h}$, followed by overnight incubation with primary antibodies diluted 1:200 at $4{ }^{\circ} \mathrm{C}$ overnight [rabbit anti-promyelocytic leukemia zinc finger (PLZF; NBP1-80894, Novus Biologicals, Centennial, CO, USA), rabbit anti-glial-derived neurotrophic factor family receptor alpha 1 (GFR $\alpha 1$; ab8026, Abcam), rabbit anti-DEAD-box polypeptide 4 (DDX4, also known as VASA; ab13840, Abcam), and mouse anti-KIT proto-oncogene receptor tyrosine kinase (c-Kit; sc-365504, Santa Cruz Biotechnology, Santa Cruz, CA, USA)], the cells were washed three times with DPBS, followed by incubation with Alexa Fluor 568-conjugated anti-rabbit IgG (A11011, Invitrogen) or Alexa Fluor 568-conjugated antimouse IgG (A11004, Invitrogen) at RT $\left(20-25^{\circ} \mathrm{C}\right)$ for $1 \mathrm{~h}$. The cellular nuclei were stained using VectaShield ${ }^{\circledR}$ mounting medium containing 4,6-diamidino-2-phenylindole (DAPI, LSBio, Seattle, WA, USA). To analyze the marker expression of $\mathrm{GFP}^{+}$germ cells (\%), a TS-1000 microscope interfaced with the NIS Elements imaging software (Nikon, Tokyo, Japan) was used. The number of labeled cells among the $\mathrm{GFP}^{+}$germ cells was calculated in five different microscopic fields by dividing them into five compartments (i.e., upper right/left, lower right/left, and center) to avoid overlap. All spots were visually evaluated, and compartments with less than 50 cells present were excluded.

\subsection{Real-Time Quantitative Polymerase Chain Reaction (RT-qPCR)}

Total RNA was extracted using the TRIzol reagent (Invitrogen) and purified using the PureLink ${ }^{\mathrm{TM}}$ RNA Mini Kit (Invitrogen) according to the manufacturer's recommendations, which was followed by quantification with the NanoDrop spectrophotometer. Total RNA (1500 ng) was used for complementary DNA synthesis with the SuperScript IV First-Strand Synthesis System (Invitrogen) and oligo-(dT) primers. RT-qPCR was performed with cDNA (300 ng) in addition to SYBR Green PCR Master Mix and each gene-specific primer [Ets variant 5 (Etv5), LIM homeobox 1 (Lhx1), DAZ-like (Dazl), and synaptonemal complex protein 1 (Sycp1); Glyceraldehyde-3-phosphate dehydrogenase (Gapdh); Table 3]. Gapdh was used as the internal control. The RT-qPCR assays were performed on a 7500 Real-Time PCR System (Applied Biosystems, Carlsbad, CA, USA) with the following conditions: initial denaturation at $95^{\circ} \mathrm{C}$ for $10 \mathrm{~min}$, followed by 40 cycles of $95^{\circ} \mathrm{C}$ for $15 \mathrm{~s}$ and $60^{\circ} \mathrm{C}$ for $1 \mathrm{~min}$ in a two-step thermal cycle, and a final melting curve step at $95^{\circ} \mathrm{C}$ for $15 \mathrm{~s}, 60^{\circ} \mathrm{C}$ for $1 \mathrm{~min}$, $95^{\circ} \mathrm{C}$ for $30 \mathrm{~s}$, and $60^{\circ} \mathrm{C}$ for $15 \mathrm{~s}$. All quantification cycle $\left(\mathrm{C}_{\mathrm{T}}\right)$ values were normalized to the Gapdh levels, and quantification was performed using the $2^{-\Delta \Delta C T}$ method.

Table 3. RT-qPCR primers.

\begin{tabular}{cccc}
\hline Gene & Forward Primer $\left(\mathbf{5}^{\prime} \rightarrow \mathbf{3}^{\prime}\right)$ & Reverse Primer $\left(\mathbf{5}^{\prime} \rightarrow \mathbf{3}^{\prime}\right)$ & Accession $\mathbf{N u m b e r}$ \\
\hline Gapdh & TGACCCCTTCATTGACCTTC & TACTCAGCACCAGCATCACC & NM_008084.3 \\
Etv5 & CCCGGATGCACTCTTCTCTATG & TCGGATTCTGCCTTCAGGAA & NM_023794 \\
L $h x 1$ & CCCAGCTTTCCCGAATCCT & GCGGGACGTAAATAAATAAAATGG & NM_008498 \\
scyp 1 & CGCTACAACCACATGCTTCG & GGAACGCTGCTTAGATCTCCTC & NM_011516 \\
Dazl & AATGTTCAGTTCATGATGCTGCTC & TGTATGCTTCGGTCCACAGACT & NM_010021 \\
\hline
\end{tabular}

\subsection{In Vivo Transplantation}

The recipient 6-week-old C57 mice were prepared by intraperitoneal injection of $45 \mathrm{mg} / \mathrm{kg}$ body weight of busulfan to exclude endogenous germ cells. Early-passage (8-11 passages) $\mathrm{GFP}^{+}$germ cells were used as donor cells and concentrated to a density of $1.0 \times 10^{6}$ cells $/ \mathrm{mL}$ for transplantation. Ketamine $(75 \mathrm{mg} / \mathrm{kg})$ and medetomidine $(0.5 \mathrm{mg} / \mathrm{kg})$ were used to anesthetize the C57 recipient mice. The C57-GFP ${ }^{+}$donor cells were transplanted into the recipient mice testes through efferent ducts, as previously 
described [29]. Two months after transplantation, the recipient mouse testes were collected, and the tunica albuginea were decapsulated to analyze colony formation. To quantify the SSCs, the number of C57-GFP ${ }^{+}$donor colonies greater than $1 \mathrm{~mm}$ in length was counted via fluorescence microscopy [30]. To determine whether the stemness of the SSCs was maintained, the number of colonies per $10^{5}$ cells transplanted, which is also known as the ratio of SSCs to $10^{5}$ cells transplanted, was calculated as follows:

Colonies $/ 10^{5}$ cells transplanted $=\left(\right.$ number of colonies $\left.\times 10^{5}\right) /$ number of transplanted cells

To demonstrate the efficiency of post-thaw recovery on the SSCs, the total number of SSCs within the recovered germ cells after freezing, thawing, and culturing was quantified as follows:

Colonies / total number of cultured SSCs after cryopreservation $=$ (number of colonies $\times$ total number of cultured cells)/number of transplanted cells

\subsection{Statistical Analysis}

All statistical analyses were conducted with SPSS version 20 (IBM; Armonk, NY, USA). The Shapiro-Wilk and Levene's tests were used to assess normal distribution and homogeneity of variance, respectively, and multiple comparisons between samples were conducted using one-way analysis of variance (ANOVA) coupled with the post-hoc Tukey's honestly significant difference test. Dunnett's test was used to determine whether each of the treatments showed a significant difference from the control for screening of dosedependent effects. All experiments were conducted at least in triplicate unless otherwise stated, and all data were reported as the mean \pm SEM. A significance level of $p<0.05$ was deemed statistically significant.

\section{Results}

3.1. Supplementation of Antioxidants or Apoptosis Inhibitors in the Post-Thaw Culture Media Improves the Proliferation Rates of Germ Cells

The relative proliferation rate was evaluated to assess the efficiency of antioxidant or apoptosis inhibitor supplementation in increasing post-thaw recovery. With normalshaped germ cell clumps (Figure 1A), the relative proliferation rate was significantly higher in the groups supplemented with HTU $400 \mu \mathrm{M}(133.7 \pm 3.2 \%), \alpha$-TCP $400 \mu \mathrm{M}$ $(158.9 \pm 3.6 \%)$, and ZDF 100 and $200 \mu \mathrm{M}(119.3 \pm 3.2 \%$ and $133.1 \pm 7.6 \%$, respectively) in comparison with the controls $(100 \pm 3.6 \%)$ in which the cells received no treatment after cryo-thawing (Figure 1B). The cells in the control group received no treatment after cryo-thawing. Therefore, we chose HTU $400 \mu \mathrm{M}$, TCP $400 \mu \mathrm{M}$, and ZDF $200 \mu \mathrm{M}$ as the optimal concentrations for assessing the benefits for post-thaw recovery and used these concentrations in all downstream experiments.

\subsection{Protective Effects of Antioxidants and the Apoptosis Inhibitor in the Post-Thaw Recovery Phase}

The ROS generation and apoptosis levels were assessed to identify the causes/mechanisms underlying the improved post-thaw recovery of frozen germ cells. Our results showed that the ROS generation level was significantly reduced by $\alpha$-TCP $400 \mu \mathrm{M}$ ( $0.8 \pm 0.0$-fold) treatment in comparison with the control group (1.0 \pm 0.0 -fold), whereas no significant difference was observed between the control group (1.0 \pm 0.0 -fold) and the HTU $400 \mu \mathrm{M}(0.9 \pm 0.0$-fold) and ZDF $200 \mu \mathrm{M}(0.9 \pm 0.0$-fold) groups (Figure 2). Although apoptosis level data showed no significant difference in late apoptosis, early apoptosis was significantly lower in the groups supplemented with $\alpha$-TCP $400 \mu \mathrm{M}(2.4 \pm 0.4 \%)$ and ZDF $200 \mu \mathrm{M}(1.8 \pm 0.4 \%)$ in comparison with the control (5.3 $\pm 1.4 \%$; Figure 3A). Additionally, the relative expression ratio of Bax/Bcl-xL was also significantly decreased by $\alpha$-TCP $400 \mu \mathrm{M}(0.5 \pm 0.0$-fold $)$ and ZDF $200 \mu \mathrm{M}(0.3 \pm 0.0$-fold $)$ in comparison with the control $(1.0 \pm 0.0$-fold; Figure 3B). Thus, our results indicate that $\alpha$-TCP $400 \mu \mathrm{M}$ and ZDF $200 \mu \mathrm{M}$ 
treatments in the post-thaw recovery phase effectively suppressed ROS generation or the apoptosis level in frozen germ cells after thawing.

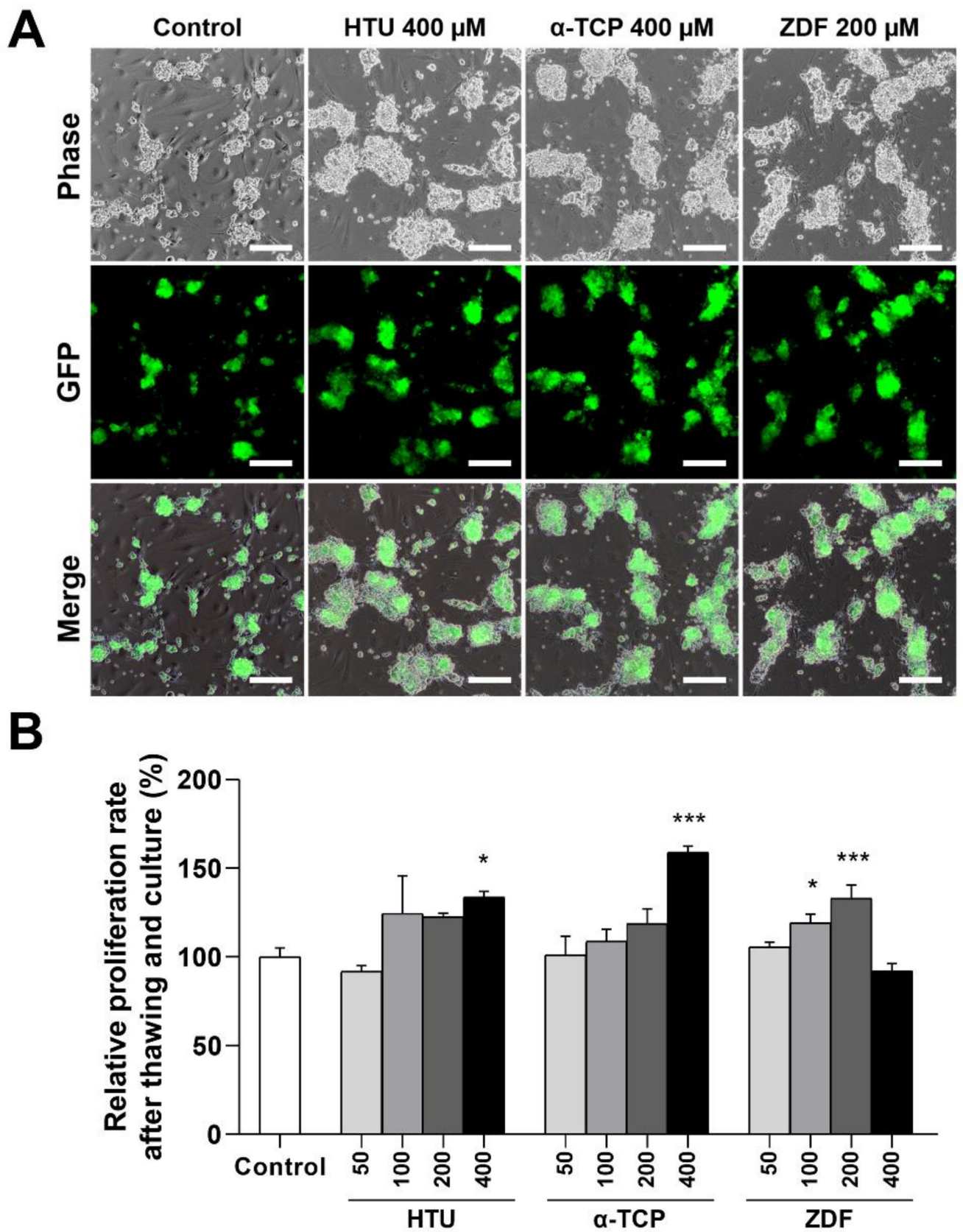

Figure 1. Effects of post-thaw recovery with antioxidant or apoptosis inhibitor supplementation on frozen germ cells. (A) Bright/dark-field images of $\mathrm{GFP}^{+}$germ cells after post-thaw recovery for $12 \mathrm{~h}$ followed by in vitro culture for one week. Scale bars $=100 \mu \mathrm{m}(10 \times)$. (B) Relative proliferation rate after post-thaw recovery with antioxidant or apoptosis inhibitor supplementation at different concentrations. The cells in the control group received no treatment after cryo-thawing. The values are expressed as the mean $\pm \operatorname{SEM}(n=5)$. Statistical analyses were performed using one-way ANOVA coupled with Dunnett's post-hoc test. Asterisks indicate statistical significance at $p<0.05(*)$ and $\left.p<0.001{ }^{* * *}\right)$. HTU, Hypotaurine; $\alpha$-TCP, $\alpha$-tocopherol; ZDF, Z-DEVD-FMK. 


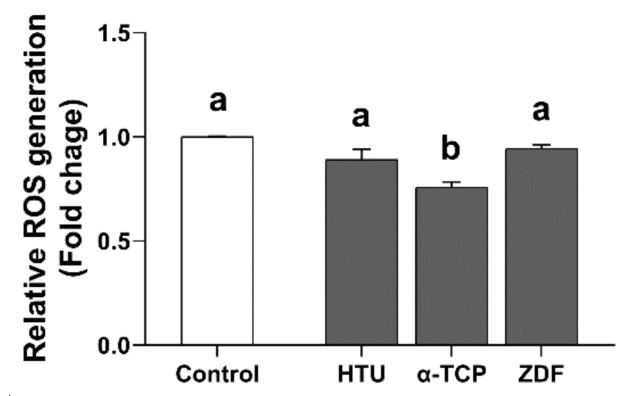

Figure 2. ROS generation in frozen germ cells after post-thaw recovery with antioxidant or apoptosis inhibitor supplementation. The ROS level was evaluated $12 \mathrm{~h}$ after post-thaw recovery in cryo-thawed germ cells. The values are expressed as the mean $\pm \operatorname{SEM}(n=3)$. Statistical analysis was performed using one-way ANOVA coupled with Tukey's post-hoc test. Different letters above each column indicate statistically significant differences $(p<0.05)$. HTU, Hypotaurine; $\alpha$-TCP, $\alpha$-tocopherol; ZDF, Z-DEVD-FMK.

A
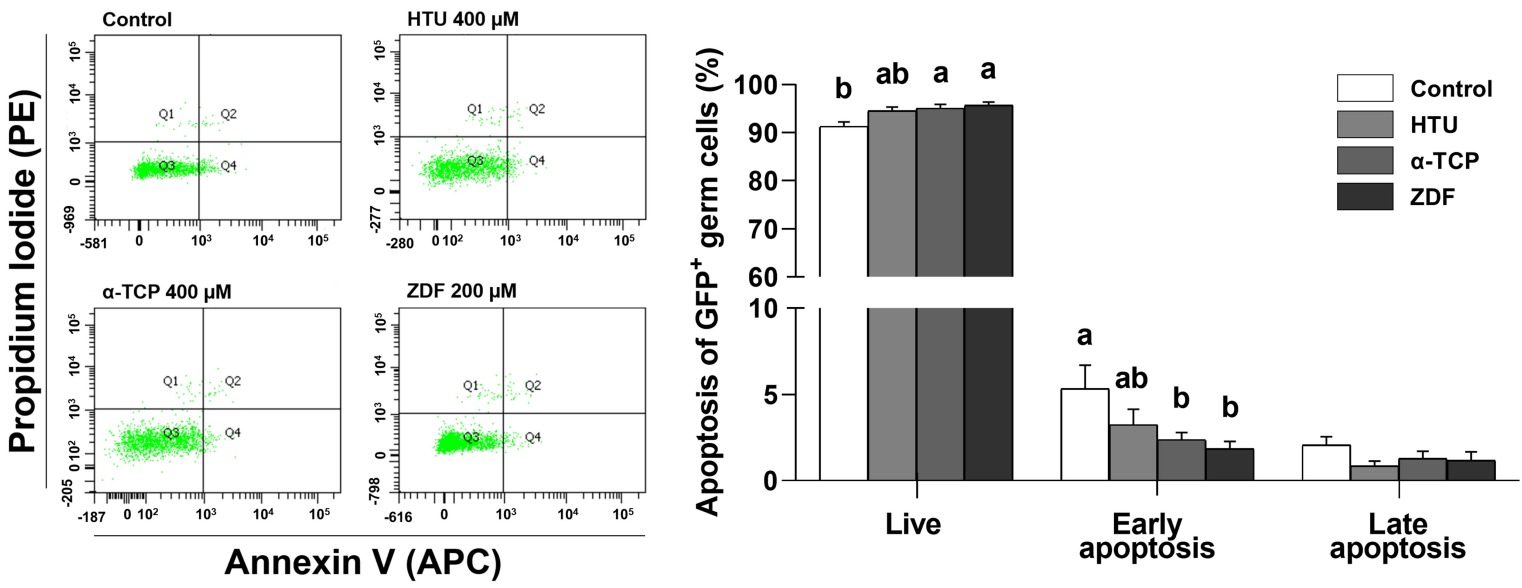

B
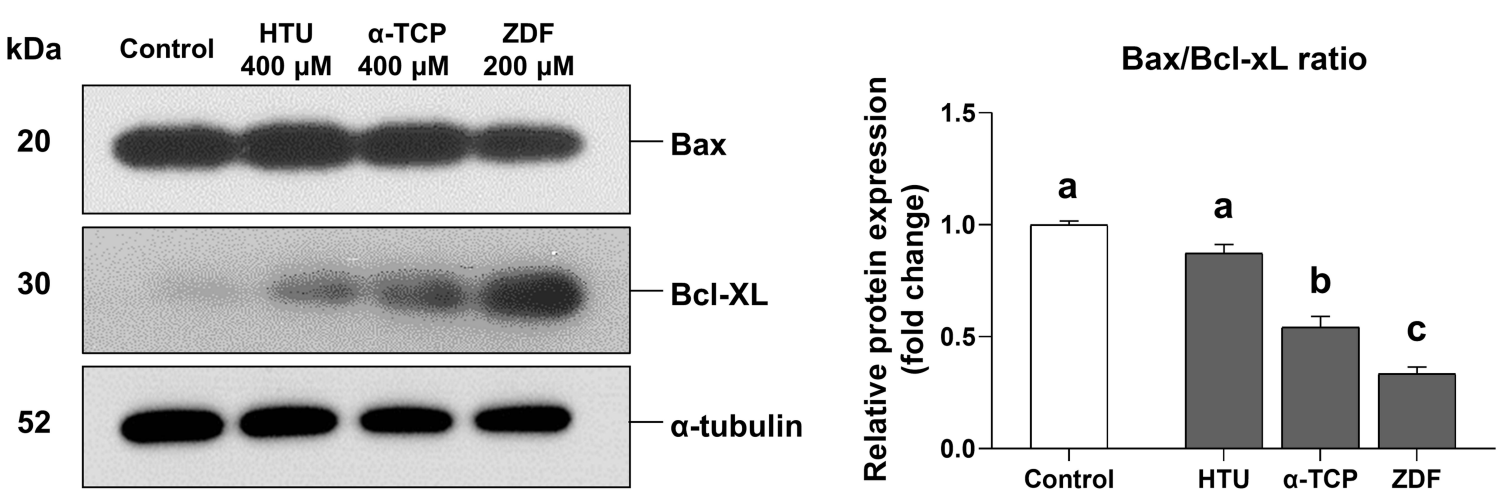

Figure 3. Apoptosis of frozen germ cells after post-thaw recovery with antioxidant or apoptosis inhibitor supplementation. (A) Early and late apoptosis in the HTU $400 \mu \mathrm{M}, \alpha$-TCP $400 \mu \mathrm{M}$, and ZDF $200 \mu \mathrm{M}$ treatment groups. Apoptosis was evaluated $12 \mathrm{~h}$ after post-thaw recovery in cryo-thawed germ cells. The apoptotic cell population is summarized in a graph. (B) Bax $/ \mathrm{Bcl}-\mathrm{xL}$ ratio determined using western blot analysis. $\alpha$-Tubulin was used as a loading control. The graph represents the quantification of protein expression, which was measured as the fold change of the treatment groups with respect to the control. The values are expressed as mean \pm SEM $(n=3)$. Statistical analysis was performed using one-way ANOVA coupled with Tukey's post-hoc test. Different letters above each column indicate statistically significant differences $(p<0.05)$. HTU, Hypotaurine; $\alpha$-TCP, $\alpha$-tocopherol; ZDF, Z-DEVD-FMK. 


\subsection{Stable Characterization after Post-Thaw Recovery with Antioxidants or Apoptosis Inhibitors}

Unlike other cells, safety assessment is especially essential for germ cell freezing because germ cells are supposed to transfer their genetic information to subsequent generations. Therefore, germ cells were characterized using immunofluorescence and RT-qPCR after post-thaw recovery with HTU $400 \mu \mathrm{M}, \alpha$-TCP $400 \mu \mathrm{M}$, or ZDF $200 \mu \mathrm{M}$ supplementation. Our immunofluorescence data showed normal expression of GFR $\alpha 1$ and PLZF (markers for undifferentiated spermatogonia) as well as VASA (a marker for germ cell lineage), with no significant difference between the control and treatment groups (Figure 4A). Likewise, the expression of c-Kit (a marker for differentiated spermatogonia) was within the normal range and showed no significant differences in all treatment groups. Similarly, RT-qPCR analyses showed no significant differences in the expression of Etv5 and Lhx1 (markers for undifferentiated spermatogonia), as well as Dazl and Sycp1 (markers for differentiated speramtogonia) among the groups (Figure 4B). Thus, our findings indicate that the normal characteristics of germ cells were maintained after post-thaw recovery with HTU $400 \mu \mathrm{M}, \alpha$-TCP $400 \mu \mathrm{M}$, or ZDF $200 \mu \mathrm{M}$ supplementation.

\subsection{Functional Activity of SSCs after Post-Thaw Recovery with Antioxidant or Apoptosis Inhibitor Supplementation}

Spermatogonial transplantation is unequivocally a crucial tool for investigating the functional activity of SSCs after post-thaw recovery with HTU $400 \mu \mathrm{M}, \alpha$-TCP $400 \mu \mathrm{M}$, or ZDF $200 \mu \mathrm{M}$ supplementation. With normal colony formation of SSCs in all groups (Figure 5A), no significant differences were observed in the number of colonies per $10^{5}$ transplanted germ cells among the control (197.3 \pm 18.0 colonies), HTU $400 \mu \mathrm{M}(164.4 \pm 45.6$ colonies), $\alpha$-TCP $400 \mu \mathrm{M}$ (199.3 \pm 24.8 colonies), and ZDF $200 \mu \mathrm{M}(205.0 \pm 22.5$ colonies $)$ groups (Figure 5B). Therefore, we concluded that the population of SSCs in $10^{5}$ germ cells was constant regardless of the treatment itself as well as the type of treatment (i.e., antioxidant or apoptosis inhibitor). However, when considering the total number of SSCs collected after post-thaw recovery with HTU $400 \mu \mathrm{M}, \alpha$-TCP $400 \mu \mathrm{M}$, or ZDF $200 \mu \mathrm{M}$ supplementation, this result could be interpreted differently. The population of SSCs in the total number of germ cells collected after post-thaw recovery showed a significant difference in the $\alpha$-TCP $400 \mu \mathrm{M}(1378.9 \pm 177.2$ colonies $)$ and ZDF $200 \mu \mathrm{M}(1387.3 \pm 150.3$ colonies) groups in comparison with the control (769.5 \pm 70.1 colonies) group (Figure $5 \mathrm{~B}$ ). However, there was no difference between the HTU $400 \mu \mathrm{M}(865.4 \pm 238.8$ colonies) and control (769.5 \pm 70.1 colonies) groups. Collectively, the findings indicate that post-thaw recovery with $\alpha$-TCP $400 \mu \mathrm{M}$ or ZDF $200 \mu \mathrm{M}$ supplementation effectively increased the collection of many SSC populations after cryo-thawing. 
A
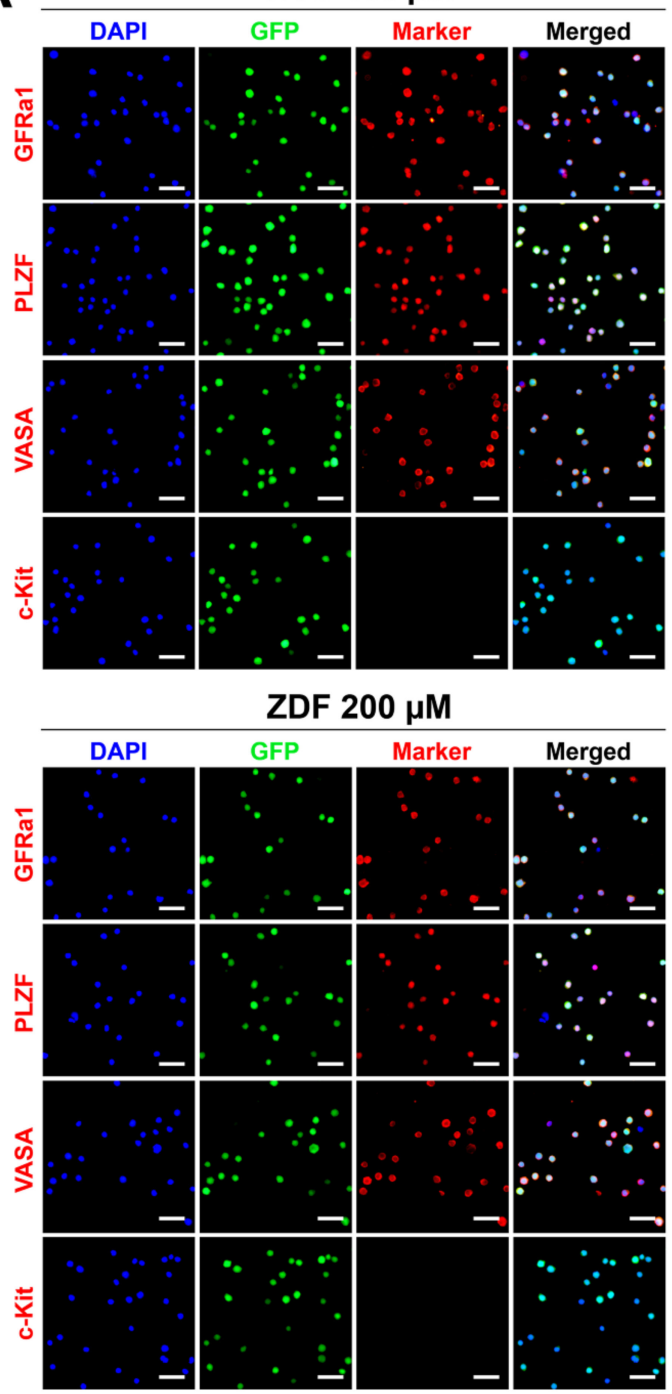
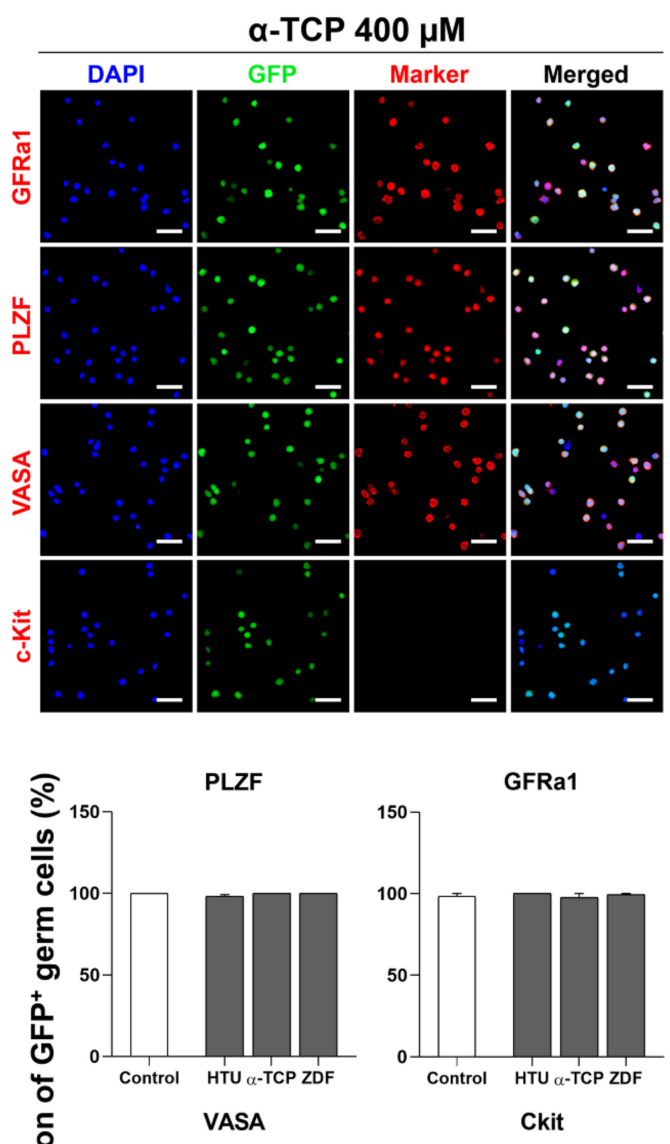

Ckit

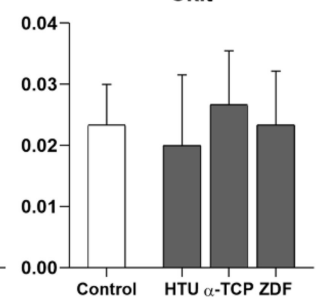

B
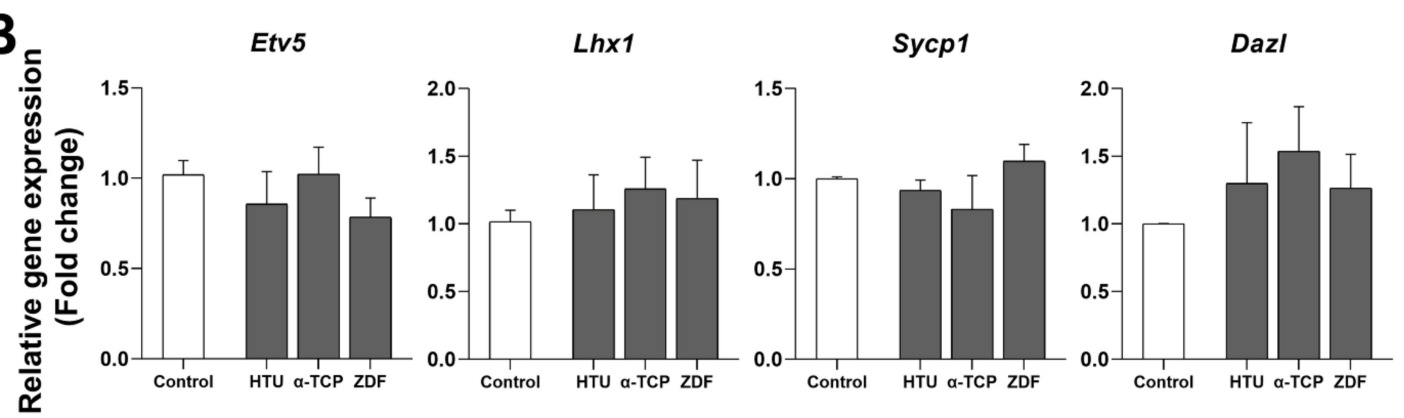

Figure 4. Characterization of germ cells after post-thaw recovery with antioxidant or apoptosis inhibitor supplementation. (A) Immunofluorescence analysis of $\mathrm{GFP}^{+}$germ cells after post-thaw recovery in the HTU $400 \mu \mathrm{M}, \alpha$-TCP $400 \mu \mathrm{M}$, and ZDF $200 \mu \mathrm{M}$ treatment groups. Representative images obtained after immunofluorescence analyses using markers (shown in red) for undifferentiated spermatogonia (GFR $\alpha 1$ and PLZF), germ cells (VASA), and differentiated spermatogonia (c-Kit). Nuclei are labeled with DAPI (blue). Scale bar $=100 \mu \mathrm{m}(40 \times)$. Marker expression in $\mathrm{GFP}^{+} \mathrm{GSC}_{\mathrm{s}}$ is summarized as a bar graph. (B) Relative gene levels of germ cells after post-thaw recovery. Genes for undifferentiated spermatogonia (Etv5 and Lhx1) and differentiated spermatogonia (Sycp1 and Dazl) are shown in relative graphical data. Values are expressed as the mean \pm SEM $(n=3)$. Statistical analysis was performed by one-way ANOVA with Tukey's test as a post-hoc test. HTU, Hypotaurine; $\alpha$-TCP, $\alpha$-tocopherol; ZDF, Z-DEVD-FMK. 
A
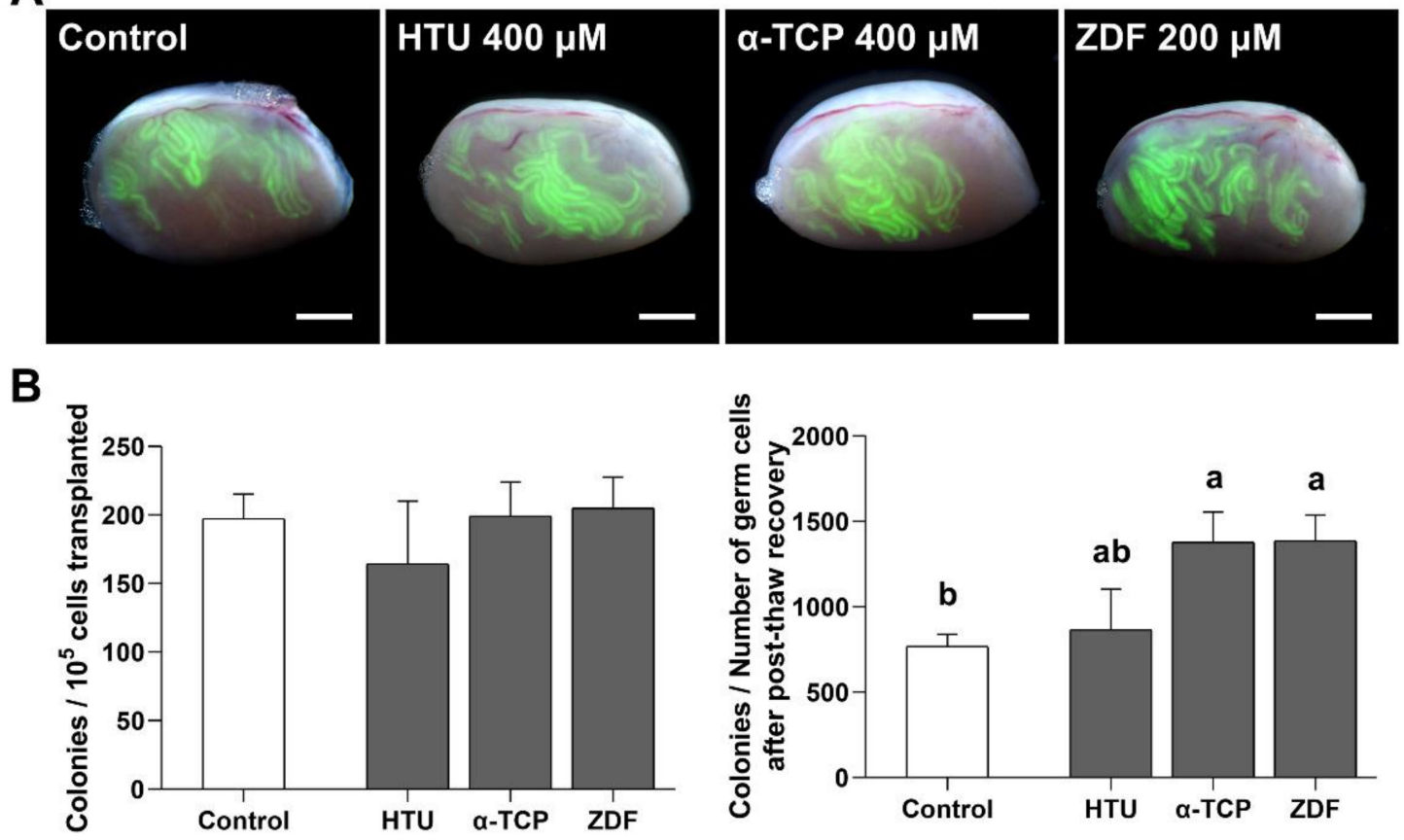

Figure 5. Functional activity of SSCs after post-thaw recovery with antioxidant or apoptosis inhibitor supplementation. (A) Merged bright/dark-field fluorescence images of C57 recipient testes after in vivo transplantation. Colonies derived from the donor C57-GFP ${ }^{+}$SSCs are formed in seminiferous tubules, which are distinguished in the C57 recipient mice. Scale bar $=2 \mathrm{~mm}$. (B) Number of colonies per $10^{5}$ cells transplanted and number of colonies per recovered germ cells after post-thaw recovery and culture. Total number of mice/testes used for analysis was $8 / 13,8 / 11,8 / 15$, and $8 / 13$ in the control, HTU $400 \mu \mathrm{M}, \alpha$-TCP $400 \mu \mathrm{M}$, and ZDF $200 \mu \mathrm{M}$ groups, respectively. Non-injected testes with a poor condition were excluded from testis analysis. Values are expressed as mean $\pm \operatorname{SEM}(n=13,11,15$, and 13 testes, respectively). A statistically significant difference $(p<0.05)$ is represented by different letters above each column.

\section{Discussion}

The development of cryoprotectants has resulted in a gradual increase in the success rates of SSC cryopreservation procedures. Nevertheless, poor post-thaw care of frozen cells can reduce the efficiency of recovery from ROS attacks after thawing. Therefore, we postulated that the post-thaw culture media with an antioxidant or apoptosis inhibitor would enhance post-thaw recovery by alleviating ROS generation and apoptosis. In this study, we aimed to develop post-thaw culture media to improve the recovery of cryothawed SSCs.

According to Murray KA et al., evaluation of total cellular recovery via post-thaw culture is crucial to assess the protective effect of a reagent in cryopreservation studies [31]. Therefore, we evaluated the proliferation rate after cryo-thawing and culturing to investigate the efficiency of supplementation with antioxidant or apoptosis inhibitors. Our results indicated that the highest relative proliferation rate of SSCs was observed with supplementation of HTU $400 \mu \mathrm{M}, \alpha$-TCP $400 \mu \mathrm{M}$, or ZDF $200 \mu \mathrm{M}$ in the post-thaw recovery phase, suggesting that cryoinjury can be alleviated by using culture media specifically designed for the care of cryo-thawed cells in addition to using an appropriate freezing medium. This may be attributed to the fact that major cryoinjuries occur in the early stage after cryo-thawing rather than during freezing [16], which is supported by a previous study reporting that exposure to apoptosis inhibitors during culture can enhance post-thaw recovery of human stem cells more than its exposure in freezing media $[7,22]$.

HTU is present in most mammalian tissue [32], and HTU-taurine metabolism shows protective effects on the male reproductive system as an excellent scavenger of ROS in vivo [33]. Moreover, HTU positively affects sperm motility, DNA integrity, and lipid 
peroxidation in humans [34]. Despite these important actions of HTU-taurine, our results showed that the exposure to HTU $400 \mu \mathrm{M}$ had no effects on ROS generation and apoptosis even though it improved the proliferation rate of cryo-thawed SSCs. This result is likely attributed to difference response to HTU between SSCs and spermatozoa because spermatogonia (including SSCs) are much more tolerant to ROS attack than spermatozoa [35]. Furthermore, since antioxidants are involved in an enormous amount of cellular biochemical process [36], HTU presumably affected SSC proliferation via an unknown mechanism rather than alleviating ROS generation and apoptosis. However, when considering transplantation data, there was no positive efficacy of hypotaurine on the recovery of true SSCs.

In our study, exposure to $\alpha$-TCP $400 \mu \mathrm{M}$ during in vitro culture enhanced the efficiency of post-thaw recovery, which is likely due to the role of $\alpha$-TCP as an antioxidant in protecting the unsaturated lipids in the cellular membrane from ROS-induced damage [37]. This is supported by our results in which ROS generation, early apoptotic cell population, and the Bax/Bcl-xL ratio were considerably reduced by post-thaw exposure of cryo-thawed SSCs to $\alpha$-TCP. Likewise, in many studies, $\alpha$-TCP has been shown to suppress cryoinjury of SSCs or sperm via its cryoprotective properties of scavenging free radicals and to prevent lipid peroxidation and/or apoptosis from cryoinjury even when $\alpha$-TCP was used in freezing media [12-14]. Therefore, this study is the first to identify that $\alpha$-TCP supplementation in post-thaw culture media strongly improves the post-thaw recovery of SSCs.

Additionally, our data showed that exposure to ZDF $200 \mu \mathrm{M}$ significantly alleviates early apoptosis and reduces the Bax/Bcl-xL ratio, indicating that ZDF can be used as an efficient culture media supplement after thawing in SSC cryopreservation. Although ZDF, a caspase-3 inhibitor, did not directly modulate ROS generation, it may have helped in indirectly suppressing cryoinjury-induced apoptosis because ROS generation is responsible for caspase-3 activation in frozen cells $[21,38]$. Interestingly, our data indicated that high doses of ZDF considerably reduced its efficiency, thus highlighting the importance of an apoptosis baseline. Previous studies have also reported that, at low to modest levels, apoptosis is essential for regulation of the normal physiological functions involved in the development and survival of multicellular organisms [39,40]. Therefore, we demonstrate that modest prevention of caspase activation by the caspase-3 inhibitor ZDF improves the post-thaw recovery of frozen SSCs.

In procedures utilizing SSCs to form sperm, quality assurance of SSCs is ultimately very important because of the ability of SSCs to transfer male genetic information to subsequent generations throughout spermatogenesis. In this study, the normal characterization and stemness of the cultured SSCs after cryo-thawing post-supplementation with HTU $400 \mu \mathrm{M}, \alpha$-TCP $400 \mu \mathrm{M}$, or ZDF $200 \mu \mathrm{M}$ indicated that SSCs maintained their normal properties without spontaneous differentiation. However, in vivo functional activity data showed that the total number of true SSCs in the collected cells was higher in only the $\alpha$-TCP $400 \mu \mathrm{M}$ and ZDF $200 \mu \mathrm{M}$ groups in comparison with the control group. We suggest that supplementation of $\alpha$-TCP $400 \mu \mathrm{M}$ or ZDF $200 \mu \mathrm{M}$ for post-thaw recovery did not negatively affect the functionality of SSCs. Unexpectedly, the total number of true SSCs was decreased in the HTU $400 \mu \mathrm{M}$ group, which is consistent with the above data showing that HTU $400 \mu \mathrm{M}$ did not perfectly protect cells from both ROS generation and apoptosis. Thus, we concluded that $\alpha$-TCP $400 \mu \mathrm{M}$ and ZDF $200 \mu \mathrm{M}$ could serve as effective additives to improve post-thaw recovery in SSC cryopreservation through protection of frozen SSCs from ROS generation and apoptosis after cryo-thawing. Additionally, further study is required to determine the beneficial effects of long-term treatment of these additives on ROS alleviation of cryo-thawed SSCs.

\section{Conclusions}

Our study demonstrated that modulation of ROS generation and apoptosis using a culture system with antioxidants or apoptosis inhibitors has a protective effect on frozen 
SSCs after thawing. Therefore, $\alpha$-TCP and ZDF improve the pro-survival response of cryothawed SSCs by reducing ROS generation and/or apoptosis, facilitating their post-thaw recovery. Taken together, our findings provide a new approach to improve SSC recovery after thawing. Thus, this protocol could facilitate more widespread use of SSCs in the livestock industry and/or male infertility clinics.

Author Contributions: Conceptualization, S.-E.J., H.-J.O., Y.-H.K., B.-J.K. and B.-Y.R.; Methodology, S.-E.J., J.-S.A., Y.-H.K. and B.-Y.R.; Validation, S.-E.J. and B.-Y.R.; Formal analysis, S.-E.J. and H.J.O.; Investigation, S.-E.J. and H.-J.O.; Resources, B.-Y.R.; Writing—original draft preparation, S.-E.J. and H.-J.O.; Wiring-review \& editing, S.-E.J., J.-S.A. and B.-Y.R.; Visualization, S.-E.J. and H.-J.O.; Supervision, B.-Y.R.; Project administration B.-Y.R.; Funding acquisition, B.-Y.R. All authors have read and agreed to the published version of the manuscript.

Funding: This research was supported by the National Research Foundation of Korea (NRF) grant funded by the Korea government (MEST), Republic of Korea (NRF-2020R1A2C1009974) and Basic Science Research Program through the National Research Foundation of Korea (NRF) grant funded by the Ministry of Education, Republic of Korea (NRF-2018R1A6A1A03025159).

Institutional Review Board Statement: Animal experiments were approved by the Animal Care and Use Committee of Chung-Ang University (Permit Number: 201900048) and the study was conducted according to the Guide for the Care and Use of Laboratory Animals published by the National Institutes of Health.

Informed Consent Statement: Not applicable.

Data Availability Statement: Data is contained within the article.

Conflicts of Interest: The authors declare no competing interests.

\section{References}

1. Griswold, M.D.; Oatley, J.M. Concise review: Defining characteristics of mammalian spermatogenic stem cells. Stem Cells 2013, 31, 8-11. [CrossRef] [PubMed]

2. Miao, X.-Y. Production of Transgenic Animals Using Spermatogonial Stem Cells. Agric. Sci. China 2011, 10, 762-768. [CrossRef]

3. Oatley, J.M. Recent advances for spermatogonial stem cell transplantation in livestock. Reprod. Fertil. Dev. 2017, 30, 44-49. [CrossRef] [PubMed]

4. Sadri-Ardekani, H.; Atala, A. Testicular tissue cryopreservation and spermatogonial stem cell transplantation to restore fertility: From bench to bedside. Stem Cell Res. Ther. 2014, 5, 68. [CrossRef] [PubMed]

5. Len, J.S.; Koh, W.S.D.; Tan, S.X. The roles of reactive oxygen species and antioxidants in cryopreservation. Biosci. Rep. 2019, 39. [CrossRef] [PubMed]

6. Xu, X.; Cowley, S.; Flaim, C.J.; James, W.; Seymour, L.; Cui, Z. The roles of apoptotic pathways in the low recovery rate after cryopreservation of dissociated human embryonic stem cells. Biotechnol. Prog. 2010, 26, 827-837. [CrossRef] [PubMed]

7. Heng, B.C.; Clement, M.V.; Cao, T. Caspase inhibitor Z-VAD-FMK enhances the freeze-thaw survival rate of human embryonic stem cells. Biosci. Rep. 2007, 27, 257-264. [CrossRef]

8. Martínez-Páramo, S.; Diogo, P.; Dinis, M.T.; Herráez, M.P.; Sarasquete, C.; Cabrita, E. Incorporation of ascorbic acid and $\alpha-$ tocopherol to the extender media to enhance antioxidant system of cryopreserved sea bass sperm. Theriogenology 2012, 77, 1129-1136. [CrossRef]

9. Martínez-Páramo, S.; Diogo, P.; Dinis, M.T.; Soares, F.; Sarasquete, C.; Cabrita, E. Effect of two sulfur-containing amino acids, taurine and hypotaurine in European sea bass (Dicentrarchus labrax) sperm cryopreservation. Cryobiology 2013, 66, 333-338. [CrossRef]

10. Ha, S.J.; Kim, B.G.; Lee, Y.A.; Kim, Y.H.; Kim, B.J.; Jung, S.E.; Pang, M.G.; Ryu, B.Y. Effect of Antioxidants and Apoptosis Inhibitors on Cryopreservation of Murine Germ Cells Enriched for Spermatogonial Stem Cells. PLoS ONE 2016, 11, e0161372. [CrossRef]

11. Partyka, A.; Rodak, O.; Bajzert, J.; Kochan, J.; Niżański, W. The Effect of L-Carnitine, Hypotaurine, and Taurine Supplementation on the Quality of Cryopreserved Chicken Semen. Biomed Res. Int. 2017, 2017, 7279341. [CrossRef]

12. Aliakbari, F.; Gilani, M.A.; Amidi, F.; Baazm, M.; Korouji, M.; Izadyar, F.; Yazdekhasti, H.; Abbasi, M. Improving the Efficacy of Cryopreservation of Spermatogonia Stem Cells by Antioxidant Supplements. Cell Reprogram. 2016, 18, 87-95. [CrossRef]

13. Aliakbari, F.; Sedighi Gilani, M.A.; Yazdekhasti, H.; Koruji, M.; Asgari, H.R.; Baazm, M.; Izadyar, F.; Kharrazi Nejad, E.; Khanezad, M.; Abbasi, M. Effects of antioxidants, catalase and $\alpha$-tocopherol on cell viability and oxidative stress variables in frozen-thawed mice spermatogonial stem cells. Artif. Cells Nanomed. Biotechnol. 2017, 45, 63-68. [CrossRef]

14. Jeong, Y.J.; Kim, M.K.; Song, H.J.; Kang, E.J.; Ock, S.A.; Kumar, B.M.; Balasubramanian, S.; Rho, G.J. Effect of alpha-tocopherol supplementation during boar semen cryopreservation on sperm characteristics and expression of apoptosis related genes. Cryobiology 2009, 58, 181-189. [CrossRef] 
15. Bissoyi, A.; Pramanik, K. Role of the apoptosis pathway in cryopreservation-induced cell death in mesenchymal stem cells derived from umbilical cord blood. Biopreserv. Biobank. 2014, 12, 246-254. [CrossRef]

16. Coundouris, J.A.; Grant, M.H.; Engeset, J.; Petrie, J.C.; Hawksworth, G.M. Cryopreservation of human adult hepatocytes for use in drug metabolism and toxicity studies. Xenobiotica 1993, 23, 1399-1409. [CrossRef]

17. Kamalifar, S.; Azarpira, N.; Sadeghi, L.; Ghorbani-Dalini, S.; Nekoei, S.M.; Aghdaie, M.H.; Esfandiari, E.; Azarpira, M.R. ROCK Y-27632 Inhibitor, Ascorbic Acid, and Trehalose Increase Survival of Human Wharton Jelly Mesenchymal Stem Cells After Cryopreservation. Exp. Clin. Transplant. 2020, 18, 505-511. [CrossRef]

18. Xiang, D.C.; Jia, B.Y.; Fu, X.W.; Guo, J.X.; Hong, Q.H.; Quan, G.B.; Wu, G.Q. Role of astaxanthin as an efficient antioxidant on the in vitro maturation and vitrification of porcine oocytes. Theriogenology 2021, 167, 13-23. [CrossRef]

19. Winn, E.; Whitaker, B.D. Quercetin supplementation to the thawing and incubation media of boar sperm improves post-thaw sperm characteristics and the in vitro production of pig embryos. Reprod. Biol. 2020, 20, 315-320. [CrossRef]

20. Truong, T.T.; Gardner, D.K. Antioxidants increase blastocyst cryosurvival and viability post-vitrification. Hum. Reprod. 2020, 35, 12-23. [CrossRef]

21. Vanhulle, V.P.; Neyrinck, A.M.; Pycke, J.M.; Horsmans, Y.; Delzenne, N.M. Role of apoptotic signaling pathway in metabolic disturbances occurring in liver tissue after cryopreservation: Study on rat precision-cut liver slices. Life Sci. 2006, 78, 1570-1577. [CrossRef] [PubMed]

22. Heng, B.C. Effect of Rho-associated kinase (ROCK) inhibitor Y-27632 on the post-thaw viability of cryopreserved human bone marrow-derived mesenchymal stem cells. Tissue Cell 2009, 41, 376-380. [CrossRef] [PubMed]

23. Oatley, J.M.; Avarbock, M.R.; Brinster, R.L. Glial cell line-derived neurotrophic factor regulation of genes essential for self-renewal of mouse spermatogonial stem cells is dependent on Src family kinase signaling. J. Biol. Chem. 2007, 282, 25842-25851. [CrossRef] [PubMed]

24. Oatley, J.M.; Brinster, R.L. Spermatogonial stem cells. Methods Enzymol. 2006, 419, 259-282. [PubMed]

25. Kubota, H.; Avarbock, M.R.; Brinster, R.L. Growth factors essential for self-renewal and expansion of mouse spermatogonial stem cells. Proc. Natl. Acad. Sci. USA 2004, 101, 16489-16494. [CrossRef]

26. Lee, Y.A.; Kim, Y.H.; Kim, B.J.; Kim, B.G.; Kim, K.J.; Auh, J.H.; Schmidt, J.A.; Ryu, B.Y. Cryopreservation in trehalose preserves functional capacity of murine spermatogonial stem cells. PLoS ONE 2013, 8, e54889. [CrossRef]

27. Nishimura, T.; Duereh, M.; Sugita, Y.; Yoshida, Y.; Higuchi, K.; Tomi, M.; Nakashima, E. Protective effect of hypotaurine against oxidative stress-induced cytotoxicity in rat placental trophoblasts. Placenta 2015, 36, 693-698. [CrossRef]

28. Lawrence, C.P.; Chow, S.C. Suppression of human T cell proliferation by the caspase inhibitors, z-VAD-FMK and z-IETD-FMK is independent of their caspase inhibition properties. Toxicol. Appl. Pharmacol. 2012, 265, 103-112. [CrossRef]

29. Brinster, R.L. Germline stem cell transplantation and transgenesis. Science 2002, 296, 2174-2176. [CrossRef]

30. Ogawa, T.; Aréchaga, J.M.; Avarbock, M.R.; Brinster, R.L. Transplantation of testis germinal cells into mouse seminiferous tubules. Int. J. Dev. Biol. 1997, 41, 111-122.

31. Murray, K.A.; Gibson, M.I. Post-Thaw Culture and Measurement of Total Cell Recovery Is Crucial in the Evaluation of New Macromolecular Cryoprotectants. Biomacromolecules 2020, 21, 2864-2873. [CrossRef] [PubMed]

32. Holmes, R.P.; Goodman, H.O.; Hurst, C.H.; Shihabi, Z.K.; Jarow, J.P. Hypotaurine in male reproduction. Adv. Exp. Med. Biol. 1992, 315, 437-441. [PubMed]

33. Jarak, I.; Almeida, S.; Carvalho, R.A.; Sousa, M.; Barros, A.; Alves, M.G.; Oliveira, P.F. Senescence and declining reproductive potential: Insight into molecular mechanisms through testicular metabolomics. Biochim. Biophys. Acta Mol. Basis Dis. 2018, 1864, 3388-3396. [CrossRef] [PubMed]

34. Donnelly, E.T.; Mcclure, N.; Lewis, S.E.M. Glutathione and hypotaurine in vitro: Effects on human sperm motility, DNA integrity and production of reactive oxygen species. Mutagenesis 2000, 15, 61-68. [CrossRef]

35. Celino, F.T.; Yamaguchi, S.; Miura, C.; Ohta, T.; Tozawa, Y.; Iwai, T.; Miura, T. Tolerance of spermatogonia to oxidative stress is due to high levels of $\mathrm{Zn}$ and $\mathrm{Cu} / \mathrm{Zn}$ superoxide dismutase. PLOS ONE 2011, 6, e16938. [CrossRef]

36. Espinosa-Diez, C.; Miguel, V.; Mennerich, D.; Kietzmann, T.; Sánchez-Pérez, P.; Cadenas, S.; Lamas, S. Antioxidant responses and cellular adjustments to oxidative stress. Redox. Biol. 2015, 6, 183-197. [CrossRef]

37. Wang, X.; Quinn, P.J. Vitamin E and its function in membranes. Prog. Lipid Res. 1999, 38, 309-336. [CrossRef]

38. Redza-Dutordoir, M.; Averill-Bates, D.A. Activation of apoptosis signalling pathways by reactive oxygen species. Biochim. Biophys. Acta 2016, 1863, 2977-2992. [CrossRef]

39. Ryoo, H.D.; Bergmann, A. The role of apoptosis-induced proliferation for regeneration and cancer. Cold Spring Harb. Perspect. Biol. 2012, 4, a008797. [CrossRef]

40. Elmore, S. Apoptosis: A review of programmed cell death. Toxicol. Pathol. 2007, 35, 495-516. [CrossRef] 